\title{
SEMIOTIKA REFORMASI HUKUM RES REPUBLIKA, RES KONSTITUSI DAN RES KETUHANAN
}

\author{
Oleh: \\ Marcus Lukman
}

Alam Semesta sarat dengan tanda-tanda kehidupan. Semua kehidupan meiliki tanda-tanda - baik ataupun buruk. Tanda-tanda itu ada yang kasat mata, ada pula yang bersifat "metabioritmik". Tuntutan reformasi adalah sebuah tanda kehidupan Ketatanegaraan dari Rakyat yang berdaulat kepada orang-orang yang didaulat memerintah. Bioritmiknya berpuncak pada 'res Republika", "Res Konstitusi" dan "Res Ketuhanan". Ritme inilah yay perlu dipelihara denyut edarnya agar tetap konstantif saling perlu menghidupkan, mensejahterakan dan mengendalikan.

\section{SEMIOTIKA ALAM SEMESTA}

Lihat di langit dan di bumi terdapat tanda-tanda bagi mereka yang beriman. Dan pada penciptaan dirimu, serta makhluk buas yang telah Allah tebarkan di atas Bumi, terdapat tanda-tanda bagi orang yang teguh imannya. Dan pergantian malam dengan siang, serta Rezeki yang Allah turunkan dari langit, yang dengan demikian menghidupkan bumi sesudah matinya, dan bertiupnya angin ini adalah tanda-tanda bagi orang yang mengerti (Q.S. 45:3-5).

Tanda, Ciri, sinyal, rambu atau jejak adalah ekspresi nilai yang melekat pada subyek dan obyek ciptaan Allah SWT, kasat inderawi maupun metafisik. Tandatanda itu, ada yang dapat diketahui seketika oleh siapapun juga. Tetapi, lebih banyak lagi yang tersamar yang hanya dapat diketahui, diekspresi, diapresiasi dan diaktualisasi oleh orang-orang yang mengerti. Bahkan, ada yang super gamma, amat tersembunyi, karena hanya Allah SWT saja yang maha mengetahui..

Dengan adanya tanda-tanda yang dapat dimengerti, semua makhluk hidup hayati maupun nabati mampu bereaksi, berevolusi dan ber-revolusi menggunakan ritme fisik, emosi, insting, dan atau intelektualnya memainkan lakon kehidupan di panggung maha ruang vertikal maupun horisontal untuk mencapai tujuan yang diinginkan di dunia dan akhirat.

Suara seekor CECAK yang melengking ketika seseorang berkontemplasi (merenung-membathin) atau manakala dua orang insan manusia bercakap, kerapkali

- Marcus Lukman adalah Dosen Univer. sitas Tanjung Pura diinteriorisasikan sebagai jastifikasi mistik sesuatu yang sedang dikontemplasi atau pun yang sedang dipercakapkan dari soal ASMARA sampai ke persoalan NEGARA.

Seseorang yang menempelkan nama Muhammad di depan nama aslinya, memberikan pertanda scyogianya berperilaku membawa visi dan misi Rasulullah Muhammad SAW, bukan sebaliknya menjadi Rasul KKN yang menyesatkan rakyat dan umat-nya.

Maka tanda-tanda yang mengekspresikan dan diekspresikan sedemikian rupa dalam wujud apapun, dalam batasbatas tertentu dapat diartikulasikan sebagai instrumen jastifikasi dari persoalan awal sampai ke persoalan akhir. Dari tiada menjadi ada atau sebaliknya, salah - benar, baik - buruk, indah-jelek, adil - zalim, dan segala sesuatu yang hendak diinterplaykan secara konkret ataupun abstrak menuju ragam simantika: Ikon, Indeks, Simbol, Qualisme, Singular, Lex Agendi Lex Assendi, dan paradigmatikanya. Relevansi genta smiotika alam semesta yang demikian itu, menjelma juga dalam kehidupan ketatanegaraan suatu negara. Penjelmaannya beraneka ragam, transparan, tersammar, tersembunyi, verbal, maupun literer. Di warung kopi, Kampus Mahasiswa, di jalan raya, maupun di Intana negara. Pendek kata di mana-mana dan menuju ke mana-mana, di semua tempat, ruang dan waktu.

Contoh aktual tentang hal itu, ialah hiruk pukunya Genta Reformasi di seluruh pelosok tanah air yang sampai kini masih memekakkan kepala para penyelenggara Negara, para pemimpin pemerintahan, para pimpinan dan anggota DPR/MPR, serta tokoh-tokoh ORSOSPOL di Republika ini. Genta Reformasi tersebut 
merupakan akumulasi, kulminasi dan kristalisasi dari akibat semiotika kontra Republika dan kontra Konstitusi rezim Orde Baru yang memerintah selama 32 Tahun.

Bangkitan Orde Baru sesunggguhnya amat sarat dengan rekayasa IPOLEKSOSBUDHANKAMNAS serba EKA dan serbi menafikan BHINEKA Ekstra Republika dan Ekstra konstitusi. Jargon kebulatan tekad yang Tunggal untuk melaksanakan kemauan Situnggal menjadi parameter standar pengayoman pemerintahan Orde Baru. Ideologi Pancasila dijadikan Asas Tunggal menurut kehendak Situngggal. Lembaga dan Aspirasi Politik Rakyat didepolitisasi dan dikendalikan oleh KKN Situnggal ala VOC. Kearifan nilai-nilai Sosial Budaya masyarakat dikorbankan demi kelancaran paradigma TriLogi pembangunan yang sebenarnya alih warisan rezim-rezim diktator Amerika latin. HANKAMNAS termasuk di dalamnya KAMTIBMAS dilogikan sebagai puncak piramida Tri Logi pembangunan. menempatkan parameter Stabilitas Nasional demi security status quo kekuasaan Situnggal. Maka tak pelak lagi seluruh sendi kehidupan ber-republik dan ber-konstitusi era pemerintahan Orde Baru semata-mata diarahkan atas PETUNJUK dari, oleh, dan untuk kemauan Situnggal.

Akibatnya, muncul gerakan reformasi untuk mengemmbalikan tata kehidupan bernegara yang berwawasan REPUBLIKA (kerakyatan), KONSTITUSI (hukum) dan KETUHANAN (Agama). Berbagai AKSI demonstrasi yang digelar dengan beragam sikap, pemikiran, pendirian, hasutan, teriakan, dan tindakan yang disuarakan oleh komponen reformasi anti KETUNGGALAN merebak di mana-mana dan kemana-mana. Situnggal pun turun dari tahtanya meninggalkan warisan rezim $\mathrm{kkn}$ yang amat sulit diberantas. Bahkan berkembanng semiotika baru, kekuatan rezim SITUNGGAL akan bangkit dengan wajah DASAMUKA berbedak reformasi.

Sementara kaum reformis sejati cenderung semakin kehilangan kharismatiknya, distikma olch ketiadaan kesatuan visi, misi, wadah, dan arah perjuangan ke depan yangg jelas. Masinggmasing komponen berggerak menurut bioritmik egosentrismenya yang persialitas.
Maka dapat dipastikan, apabila Ide, Visi, Misi Substansi, Fondasi, Dinammika dan Progresifitasnya ke depan tidak dikembalikan kepada cita rasa paham Republika, paham Konstitusi dan paham Ketuhanan yang benar, Negara dan Bangsa ini hanya merupakan arena pertarungan ulang-antar rezim pemerintahan yang buruk kepada rezim pemerintahan yang buruk. Siapakah yang memenangkan pertarungan ulang itu?Jawabannya pasti rezim pemerintahan terburuk.

\section{SEMIOTIKA HUKUM}

Semiotika berasal dari kata latin "semeon" artinya tanda, jejak, sinyal, ciri, atau rambu. Tanda, jejak sinyal, ciri, atau rambu yang berinterplay dengan hukum, inhaeren pada norma hukum a quo. dapat dipreposisikan, tanpa semiotika hukum tidak munggkin ada norma hukum.

Apabila peraturan hukum dibedah sampai kepada akar-akarnya yang terdalam, akan diperoleh IKON semiotikanya yang bersifat Holitik, Positivistik dan Pragmatis. IKON norma hukum Holistik bersumber pada nilai Ketuhanan, Kealaman dan Kemanusiaan bersifat inhaeren pada tujuan hukum yang beradabb, ialah Keteraturan, Ketertiban, Ketentraman, Kepastian, Kebenaran, dan keadilan Hukum. IKON pragmatisnya merekat pada Subyek, Obyek, Kondisi, dan Operator Norma. Kemudian IKON tersebut diinterplaykan membentuk hu bungan sebab akibat yang disebut INDEKS dalam bentuk konsep peristiwa hukum, hubungan hukum dan akibat hukum. Untuk kemudian menciptakan LEX AGENDI LEX ASSENSI ialah rumusan hukum normatif keondisional, faktual, umum, konkret, indivudual, Publik, Privat, tertulis dan tidak tertulis. Dinormativisikan melalui proses paradigmatisasi cita hukum konstitutif dan regulatif (ius constituendUm) menuju terbentuknya hukum positif bermanfaat bagi kesejahteraan dan kemakmuran bangsa (ius constitutum) secara berkelanjutan sesuai tantangan zaman, gunan memanusiakan kehidupan manusia berdasarkan atas hukum. Bagi bangsa Indonesia Ekstase semiotika hukum holistiknya sudah disepakati diapresiasikan, diekspresi, diinteriorisassi, diaktualisasi, dan dikumulasi 
mengkristal menjadi ideologi Negara atau falsafah kehidupan bangsa, yang tiada lain adalah Pancasila sebbagai sumber dari segala sumber hukum di Indonesia, serta UUD 1945 sebagai Konstitusi (Hukum Dasar) tertulis yang Tertinggi.

\section{RES REPUBLIKA, RES KONSTITUSI DAN RES KETUHANAN}

Repubilka adalah bentuk pemerintahan negara yang bersumber pada aspirasi dan pemikiran orang banyak Aspirasi dan pemikiran orang banyak dikonsepsikan berkedaulatan rakyat, diyakini lebih baik daripada aspirasi, pemikiran, dan kemauan orang yang TUNGGAL atau SEGOLONGAN orang. Sebab, menurut sifat KODRATINYA setiap individu insan manusia apapun derajat kualifikasinya, amat pekat dengan talenta ketidaksempurnaan. Maka terbuka peluang bagi pemerintahan KETUNGGALAN untuk melakukan kesalahan, rekayasa, penyelahgunaan kekuasaan, sewenang-wenang, dan kediktatoran memerintah. Oleh karena itu, bentuk pemerintahan Republik menjadi pilihan terbaik negara-negara modern yang memiliki geografi luas, demografi multi etnis, dan nilai sosial budaya Bhineka.

Bentuk pemerintahan Republik yang bersumber pada paham Kedaulatan Rakyat, dikepalai oleh seorang Presiden atau Perdana menteri -- dipilih oleh rakyat secara langsung maupun tidak langsung melalui pemilihan umum. Rakyat diposisikan sebagai pemegang kedaulatan tertinggi, memiliki kedudukan, hak dan kewajiban yang sama untuk memilih, dipilih, memerintah dan diperintah. Sedangkan Presiden atau Perdana Menteri hanyalah seorang wakil rakyat terpilih untuk memimpin organisasi pemerintahan guna melaksanakan amanat kedaulatan rakyat. bertentangan dengan amanat kedaulatan rakyat berarti menentang paham republik, paham Konstisui dan paham Ketuhanan.

Bangkitan bentuk pemerintahan Republik yang bersumber pada paham Kedaulatan Rakyat dan dipimpin oleh Presiden atau Perdana Menteri, eksistensinya melahirkan konsep sistem pemerintahan Presidensial dan Parlementer. Kedua sistem pemerintahan ini, penyelenggaraannya dikontrol langsung oleh
Rakyat melalui badan legislatif (parlemen). Di sinilah keutamaan bentuk pemerintahan Republik dibandingg bentuk pemerintahan monarche absolut yang tanpa kontrol lembagga kerakyatan (legislatif).

Sebaliknya pada paham Konstitusi proses bangkitannya berdasar pada konsep Negara Hukum yang menciptakan paham Kedaulatan Hukum. Di mana Kekuasaan negara tunduk pada Hukum dn Konstitusi menjadi Hukum Dasar tertinggi yang mengatur seluk beluk kekuasaan negara untuk mencapai tujuan negara. (Lihat Pula, Muhammad Tahir Azhary, negara Hukum, 1992)

Konstitusi, juga berfungsi untuk menjamin dan melindungi Hak Asasi Manusia (Warga Negara) baik sebagai makhluk ciptaan Allah maupun sebagai makhluk sosial. Mengatur susunan organisasi dan hubungan kekuasaan antar organ-organ Negara, serta hubungan antara yang memerintah dengan yang diperintah (Sri Soemantri, 1995: 99. 109), termasuk juga pembatasan kedudukan dabn kekuasaan Presiden dan perdana Menteri (Eksekutif).

Pengaturan seluk beluk kekuasaan Negara berdasarkan Konstitusi, baik di negara-negara yang menganut paham republik kesatuan, Republik Federalis, maupun monarche konstitusional, bertujuan untuk mencegah dan menindak terjadinya pemerintahan yang korup. Karena, seperti didalilkan oleh Lord Acton, bahwa: "Power tends to corrupt, absolute power corrupt absoluttly" (Sri Soemantri, Ibid). Korupsi terbberatdalam kehidupan ketatanegara, ialah korupsi terhadap Kedaulatan Rakyat dan Kedaulatan Hukum, sebagaimana yang dilakukan oleh Rezim pemerintahan Orde Baru. Maka persoalannya, dapatkah cita rasa, visi dan misi reformasi ekonomi, politik dan hukum yang digemakan melalui teriakan reformasi dewasa ini, diwujudkan secara total? Inilah tantangan ke depan yang perlu diperjuangkan terus menerus, agar Negara kesatuan republik Indonesia tidak diperintah ulang oleh rezim-rezim pemerintahan buruk berwawasan KETUNGGALAN.

Dari sudut pandangan paradigmatis holistik, reformasi politik dan hukum merupakan prasyarat utama (conditio sine quanon) bagi reformasi 
ekonomi. Sebab, semiotika tuntutan reformasi sudah jelas bersifat holistik, meskipun parsialitasnya di sana sini dilakukan secara positivistik dan pragmatis. Sifat holistik genta Reformasi itu, ialah Rakyat menginginkan kedaulatan Rakyat dan kedaulatan Hukum Ditegaskan secara murni dan konsekuen.

Tegasnya penetapan keanggotaan MPR, DPR dan DPRD yang representatif -sepenuhnyadipilih melalui Pemilihan Umum secara langsung, umum, bebas, rahasia, jujur, dan adil. Serta terpilihnya Presiden, Wakil Presiden dan Kabinet pemerintahan yang bersih dari rezim pemerintahan Ordc Baru dan KKN gaya baru. Tanpa kedua reformasi tersebut, amat muskil melakukan reformasi ekonomi yang berwawasan kesejahteraan rakyat. Malahan jika tidak diwaspadai dengan cermat, amat terbuka kemungkinan bahwa Rezim Soehartois diprediksikan mampu berkuasa kembali, yang berarti ORDE KETUNGGALAN akan tetap laten memerintah jagad raya Negara Kesatuan republik Indoensia.

Demikian kelangsungan perjuangan reformasi total, tiada jalan lain yang harus dilakukan oleh kaum reformais ialah secara holistik kembali kepada wawasan Negara republik dan wawasan Konstitusional serta wawasan Ketuhanan. kembali kepada wawasan republik dan wawasan Konstitusi berarti mengembalikan Kedaulatan Hukum kepada Konstitusi.

Mengembalikan kedaulatan Rakyat kepada Rakyat dan mengembalikan Kedaulatan Hukum kepada Konstitusi, berrarti seluruh penyimpangan-penyimpangan terhadap Kedaulatan Rakyat dan kedaulatan Hukum wajib dibasmi sampai kepada akar-akarnya yang terdalam. Akar-akar terdalam penyimpangan terhadap Kedaulatan rakyat dan Kedaulatan Hukum selain populer dengan sebutan KKN, tetapi yang lebih fundamental lagi iallah membasmi penyebab penyakit KKN dimaksud, yaitu KEFIRAUNAN ATAU EGOSENTRISME IALAH PENYAKIT HATI YANG MENYELIPUTI SETIAP INSAN MANUSIA.
Penyakit hati itu, amat beragam coraknya, bersumber dari Jiwa Rendah Individualistik Manusia atau hawa Nafsu yang berinterplay dengan serba materi dan immaterui keduniawian yang setiap detik selalu berkontraksi melebar dan menyempit berlawanan dengan Jiwa Suci Ketuhanan. Maka, jalan terbaik memuluskan perjalanan hidup Negara dan Bangsa Indonesia ke masa depan, agar terbebas dari jiwa Kefirauan, adalah dengan manghayati dan melaksanakan Jiwa republik (Kerakyatan) dan Jiwa Konstitusional (Hukum) yang dilandasi Jiwa Ketuhanan (Agama). Trilogi Jiwa kenegaraan tersebut wajib tertanam disanubari seluruh Rakyat Indonesia, baik berposisi sebagai pemimpin maupun yang dipimpin agar kehidupan bermasyarakat, berbangsa dan bernegara mampu mengantarkan seluruh jiwa raga Rakyat Indonesia ke akam nilai kehidupan hakiki di dunia mapun akhirat (Dalami Pula, Nurcholis Madjid, 1995: 156-161).

Penjabaran lebih lanjut Tri Logi Jiwa kenegaraan tersebut perlu dirumuskan ulang sedemikian rupa oleh segenap komponen bangsa yang bervisi reformis menuju hari depan Negara Kesatuan republik Indonesia yang Demokratis, Berdasarkan Hukum dan Berketuhanan, saling menghidupi, mensejahterakan dan mengendalikan -- zahir maupun bathin. Sekali lagi tetaplah Res republika, Res Konstitusi dan Res Ketuhanan.

\section{DAFTAR BACAAN}

Muhammad Tahir Azhary, Negara Hukum, Suatu Studi tentang prinsip-prinsipnya Dilihat dari segi Hukum Islam, Implementasinya pada Periode negara Madinan dan Masa Kini, Bulan Bintang, Jakarta, 1992 ..

Nurcholish Madjid, Islam kemodernan Dan keindonesiaan, Mizan, Bandung, Cetakankelima, 1995.

Sri Soemantri dkk, Bunga Rampai Pembangunan Rampai Pembangunan Hukum Indonesia, Eresco, Bandung, 1995 